\title{
EXPLORATION OF CAPABILITY AND ROLE DEVELOPMENT IN AN EMERGING TECHNOLOGY NETWORK
}

\begin{tabular}{|r|l|}
\hline Journal: & Journal of Business and Industrial Marketing \\
\hline Manuscript ID & JBIM-09-2017-0211.R3 \\
\hline Manuscript Type: & Original Article \\
\hline Keywords: & $\begin{array}{l}\text { Business network, Commercialization, Emerging technology, } \\
\text { Nanotechnology, Developing economy, Dynamic capability }\end{array}$ \\
\hline \multicolumn{2}{|l}{} \\
\hline
\end{tabular}

\section{SCHOLARONE ${ }^{\text {w }}$ \\ Manuscripts}




\section{EXPLORATION OF CAPABILITY AND ROLE DEVELOPMENT IN AN EMERGING TECHNOLOGY NETWORK}

\section{Purpose}

The purpose of this study is to investigate the capabilities and roles of three types of actors, specifically technology-based start-ups, incumbent firms, and intermediaries, in coconstructing a network for development and commercialization of an emerging technology. In particular, the research aims to understand how the roles played by network actors evolve during the development and commercialization process and what operational and dynamic capabilities are developed by actors through collaboration.

\section{Design/methodology/approach}

A single longitudinal case study methodology was applied to analyse roles and operational and dynamic capabilities developed in a network setting by multiple parties over time.

\section{Findings}

The findings indicate that actors need to take on new roles to be successful when dealing with an emerging technology in a network context and they need to develop certain dynamic capabilities to enact these roles. The study categorizes roles and capabilities of network actors through various stages of collaboration. Actors developed sensing capabilities in the precollaboration stage which drove joint new product development. During the collaboration, seizing capabilities were developed where resource commitment and alignment of resources among actors were essential. Capabilities gained through commercialization and large-scale production were predominantly transforming capabilities where actors realigned their structure and had positive impact on capability development in the wider network.

\section{Research limitations/implications}

Using a single case data may limit the applicability of the findings, which calls for future research.

\section{Practical implications}

The findings inform managers' and policy makers' strategies related to participation in networks for development and commercialization of emerging technologies. The research provides insights about the role of large and small firms as well as intermediary organizations in development of nanotechnology and highlights that all network actors need to develop and utilize dynamic capabilities in all areas of sensing, seizing and transforming over time to be able to innovate and successfully commercialize a new product.

\section{Originality/value}

The research investigates evolution of operational and dynamic capabilities and roles of multiple actors over time in collaborative networks for development and commercialization of an emerging technology. Building on the dynamic capabilities concept, the study broadens our understanding of the evolution of these capabilities in a network setting and elaborates how capability development is linked to changes in roles. 


\section{Keywords}

Business network; Commercialization; Emerging technology; Role; Dynamic capability; Nanotechnology; Developing economy 


\section{Introduction}

Despite the value creation potential of emerging technologies, markets for these technologies are characterized by high levels of risk, uncertainty, and increased interdependencies among firms (Easingwood and Koustelos, 2000; Ford et al., 2003). Establishing successful relationships and networks is vital for both new entrants to the field of emerging technologies and established businesses (Story et al., 2009; Ansari and Krop, 2012). New entrants such as technology-based start-up firms are usually considered as "incubation rooms" for emerging technologies (Möller, 2010). While these firms play a technology-bringing role, the function of transforming emerging technologies to something valuable to the industry is often carried out with the help of incumbent firms (Genet et al., 2012). Incumbent firms have established networks and markets. They are usually large in size and rich in resources, and have deep practical knowledge of the industry (Ansari and Krop, 2012). Some technology-based startups seek to break into the established networks of incumbent firms to obtain the necessary resources and capabilities and commercialize their technologies through alliances with them. This strategy is usually of interest to those start-ups that do not have downstream competencies and their technologies largely affect upstream activities of incumbents' value chains (Maine and Garnsey, 2006). These start-ups use relationships with incumbents to gain access to the incumbents' downstream regulatory, marketing, and sales networks; because it would be very expensive and time consuming for small firms to build those assets (Rothaermel, 2001).

While both incumbents and start-ups can benefit from collaborative arrangements, which essentially constitute the matching of complementary resources and capabilities, they face formidable challenges in developing working relationships in the context of emerging technologies (Story et al., 2011). Developing such relationships often necessitates the presence of innovation intermediaries (Howells, 2006), who can help start-ups and incumbent firms in co-construction of the network. According to Winch and Courtney (2007), an innovation intermediary can be defined as "an organization acting as a member of a network of actors in an industrial sector that is focused neither on the organization nor the implementation of innovations, but on enabling other organizations to innovate" (p.751). Intermediaries such as government organizations can act as brokers and facilitate the development of networks as a vehicle for acquisition of necessary resources and capabilities (Yam et al., 2011).

This research focuses on the analysis of the capabilities and roles of these three types of actors, specifically technology-based start-ups, incumbent firms, and intermediaries, in coconstructing a network for development and commercialization of an emerging technology. In particular, the research aims to understand how the roles played by network actors evolve during the development and commercialization process and what capabilities are developed by actors through collaboration. To do so, we use the dynamic capabilities concept as it provides a suitable framework to study development of capabilities of diverse actors in the new product development process and perfectly fits with the development of emerging technologies (Teece, 2007; Zhang and Wu, 2017; Preikschas et al., 2017; Nordin et al., 2018). Existing research does not fully investigate the evolution of these operational and dynamic capabilities and actor roles over time (Aarikka-Stenroos et al., 2014). Also, the link between role changes and capability development has not been systematically investigated in the 
existing literature (Story et al., 2011). Therefore, our research question is: How do the capabilities and roles developed/played by network actors over time support the development and commercialization of new products which embed emerging technologies?

The findings of our longitudinal empirical study broaden our understanding of development and evolution of dynamic capabilities in a network setting and reveal how these capabilities evolve and are linked to actor roles over time. Our contribution is three-fold, first we show that the dynamic capabilities that drive innovation and commercialization evolve sequentially for individual actors. We also illustrate that as one actor develops these dynamic capabilities its partners can also begin to develop complementary dynamic capabilities, which result in successful innovation in the network. Finally we illustrate that the development of dynamic capabilities demands the development of and enactment of new roles.

This paper is structured as follows. The next section provides a brief review of the literature on roles, operational and dynamic capabilities involved in development and commercialization of emerging technologies with a focus on technology-based start-ups, incumbent firms, and intermediaries. Then, the research context is briefly explained. After that, the methodology of the paper and an overview of the companies under study are presented. Finally, the findings of the study are presented, discussed and a conclusion is drawn.

\section{Roles and Capabilities in Emerging Technology Networks}

The innovation process is increasingly viewed as having an inter-organizational nature because of the many benefits networks bring for innovation. These benefits include collective efficiency, collective learning, collective risk-taking and intersection of different knowledge sets (Tidd and Bessant, 2013). Other benefits include combining skills and physical assets, technology complementarity, reduction of uncertainty, reduction of the innovation time-span, accessing market and influencing the market structure (Hagedoorn, 1993; Powell, 1998; Ahuja, 2000).

Prior research has shown that both small and large organizations need to push for greater levels of networking in their innovation processes and use relationships as a mechanism to increase their capacity for emerging technologies (e.g. Birkinshaw et al., 2007; Zeng et al., 2010; Hemert et al., 2013; Reypens et al., 2016). However, forming and managing networks that can transform emerging technologies to new industries, i.e. link technological discovery to a worthwhile and dynamic market opportunity is particularly complex, highly risky, costly, and prone to failures (Hung and $\mathrm{Chu}, 2006$ ). A wide range of capabilities and certain actor roles are necessary to complete this value-adding process (Nyström et al., 2017). Firms must enlarge the scope of their capabilities in order to recognize where the innovation value resides in the network (Perks and Jeffery, 2006). The usefulness of a firm's capabilities and the way in which these capabilities develop are determined by interaction with another firms (Gulati, 1999; Möller and Törrönen, 2003). To create valuable capabilities a firm must therefore consider how it will be viewed in relationships and how its capabilities will contribute to further development by combining with the capabilities of the other party in the relationship (Möller and Svahn, 2003; Johnsen and Ford, 2006). 
To study evolution of capabilities within organizations and in a network setting, a multi-level perspective can be adopted where we distinguish between organizational capabilities that are required to perform core activities of the firm and contribute to firm heterogeneity (i.e. operational capabilities) and dynamic capabilities that are higher level routines for adapting operational routines and capabilities to dynamic environments (Winter, 2003; Teece, 2007; Salvato and Rerup, 2011). Dynamic capabilities are the sensing, seizing, and transforming competencies that aggregate and direct the various ordinary capabilities (Teece, 2007; 2018) and are most relevant for innovation/new product development and addressing the problems or opportunities the company is endeavouring to solve or exploit (Teece and Pisano, 1994; Eisenhardt and Martin, 2000; Zhang and Wu, 2017; Preikschas et al., 2017; Nordin et al., 2018). Sensing is the capability of identifying, shaping and assessing opportunities outside the company, seizing is concerned with identifying a strategy to exploit the opportunity and necessitates mobilizing resources to capture value from those opportunities, and transforming requires refining the strategy and continuous renewal (Teece, 2007).

Since dynamic capabilities are multi-faceted, firms' strengths in each may vary (Teece, 2018). To be able to profitably build resources and ordinary capabilities, reconfigure them to innovate and respond to changes in the market, firms need strong dynamic capabilities in all areas of sensing, seizing, and transforming (Teece, 2018).Moreover, the firm's dynamic capabilities must be coordinated with the activities of partner firms to deliver value to customers (Teece, 2018). Capability development and renewal requires encouraging and motivating internal units of the organization and external collaborators to actively participate in experimenting to develop novel solutions (Salvato, 2009). Promoting diversity of external collaborators is a mechanism to increase the number of opportunities to improve capabilities (Salvato, 2009). The following sections discuss the roles and capabilities of three different types of network actor, namely technology-based start-ups, incumbent firms, and intermediary organizations that can be involved in the development and commercialization of emerging technologies.

\subsection{Role of Technology-based Start-ups in Emerging Technology Networks}

Emerging technologies are most frequently pioneered by new technology-based start-ups (Rothermal and Hill, 2003; Yu and Hang, 2010), but they do not possess all the necessary resources and capabilities for creating commercial value from their technologies. Many of these technology-based companies need to collaborate with established firms to commercialize their technologies and develop necessary capabilities through alliances with them (Hagedoorn, 1993; Harryson, 2008). Collaboration with incumbent firms is usually of interest to those technology-based companies that do not have downstream capabilities and their technologies largely affect upstream activities of incumbents' value chains (Maine and Garnsey, 2006). Through alliances with incumbent firms, start-ups can gain access to the incumbents' downstream regulatory, marketing, and sales networks, which are very expensive and time consuming for start-ups to build (Hill and Rothaermel, 2003). Collaborations between start-ups and incumbents have been extensively observed in the biotechnology industry where the start-ups played a key role in the process of co-producing and translating knowledge and bridging the gap between public research institutions and large incumbent firms (Rothaermel and Thursby, 2007; Mowery, 2011). In particular, some biotech start-ups buy research outputs from their discoverers, develop or refine them towards specific objectives, and then sell this knowledge/technology on to larger partners for downstream 
commercialization (Zucker and Darby, 1997; Genet et al., 2012). According to AarikkaStenroos et al. (2014), technology-based start-ups should identify and motivate relevant actors for commercialization and this requires understanding of the potential partners' perspectives on innovation diffusion/adoption and their goals, and finding ways of involving them in commercialization.

\subsection{Role of Incumbent Firms in Emerging Technology Networks}

It has been suggested that incumbent enterprises do not normally pioneer emerging technologies and lack the capabilities to do so (Rothaermel and Thursby, 2007; Ansari and Krop, 2012). There are, of course, exceptions to this depiction and a small number of large incumbent firms have been the originators of radical technological innovations, but incumbents are largely considered as sources of incremental innovations (Yu and Hang, 2010).

Scientific breakthroughs present both opportunities and challenges to incumbent firms (Rothaermel and Thursby, 2007). Emerging technologies create new market opportunities while simultaneously damaging, destroying, or transforming demand in many existing product markets (Hill and Rothaermel, 2003). Hindrances that incumbent firms have to overcome in emerging technologies include organizational inertia, the embeddedness of incumbents within an established network that skews information, and the prior strategic commitments of incumbents (Yu and Hang, 2010; Ansari and Krop, 2012).

Despite such difficulties, there have been successful incumbent firms who get out in front of the change, prosper in exploiting the emerging technology and experience sustained performance. This is especially true in the context of emerging enabling technologies, such as nanotechnology and biotechnology in which incumbent firms deploy these technologies in cooperative relationships with technology-based start-ups (Rothaermel and Thursby, 2007). According to Genet et al., (2012), while small technology-based firms play a valuable "technology-bringing" role, the central capability of "translating" or transforming new technology to something of value to the industry is carried by the larger incumbent firms. Examples are seen in the current development of nanotechnology and also the early stages of development of the microelectronics industry, where their development necessitated the kinds of large and diversified knowledge base capabilities that exist in large firms (Rampersad et al., 2010; Genet et al., 2012).

\subsection{Role of Intermediaries in Emerging Technology Networks}

Both incumbents and technology-based start-ups face challenges in developing working relationships in the context of emerging technologies (Story et al., 2009; Lambe and Spekman, 1997). In response to these challenges, intermediary organizations have the potential to offer additional capabilities which are needed for development of emerging technologies (Howells, 2006). These intermediaries could be governmental bodies who provide incentives and financial support for the establishment of such partnerships. Alternatively, they could be private intermediate firms who seek to utilize their networking capabilities to make connections among these firms (Yam et al., 2011). In addition to connecting other actors, intermediaries can integrate activities across the network and endorse the relationships in the network (Story et al., 2011; Tran et al., 2011). Actors performing these roles could bring 
supporting capabilities which are required for development of emerging technologies through networks.

Intermediary government organizations can also encourage firms, particularly technologybased start-ups, to undertake collaborations with organizations possessing complementary knowledge (Caloffi, Rossi and Russo, 2014). In their longitudinal study of a set of Italian small and medium sized firms that have participated in several innovation networks funded by the regional government, Caloffi et al. (2014) found that the involvement in these supported networks changed the firms' relational patterns, leading them to collaborate with a wider variety of agents than those with whom they were linked before the support policies.

Colombo et al. (2006) also refer to the facilitator role of sponsor institutions such as public research organizations, venture and corporate venture capitalists in alliance formation of innovative small firms. Their research indicates that sponsorship can reduce high transaction costs faced by smaller firms and perform a key information intermediation function to their advantage (Colombo et al., 2006). Furthermore, Cabanelas et al. (2013) found that the inclusion of intermediaries between the market and industry (i.e. border agents) is fundamental to develop innovations at the intersection of different scientific and technological disciplines.

\section{Research Context}

There is uncertainty about the different roles that small start-ups as well as larger companies play in the development of nanotechnology (OECD, 2010). Laredo (2008) and Rothaermel and Thursby (2007) emphasize the important role of incumbent firms in nanotechnology development because of their early involvement in this domain. On the other hand, Shapira and Youtie (2011), Andersen (2011) and OECD (2010) support the view that start-ups also play a significant role in nanotechnology commercialization along with large and established firms.

It is not surprising that both start-ups and large incumbent firms face several challenges in development and commercialization of nanotechnology. Poor process scalability of R\&D, i.e. challenges in the transition from R\&D to pilot and industrial scale production, is the most pervasive commercialization challenge for both start-ups and incumbent firms (OECD, 2010). Moreover, difficulties in communicating the value proposition of applications to potential customers, experimenting with multiple applications in various industries and business environments, and high uncertainty in both technology and markets constitute barriers to entry into established value chains and to the commercialization of nanotechnology (Maine et al., 2012).

Pandza and Holt (2007) emphasize the need for collaborative efforts of diverse actors including universities, start-ups, incumbent firms, and intermediaries for successful development of nanotechnology. They refer to the role of universities and start-ups as the supply side (sources of knowledge) in collaboration and established firms as the demand side which can drive the development and commercialization of nanotechnology. Intermediaries can play a supporting role by helping other actors experiment with nanotechnology, identify complementary resources and strategically appropriate technological innovations (Pandza and Holt, 2007). 
The study context is the construction industry in Iran and explores the collaborative network formed to develop silent pipes for water and wastewater in buildings. The new product is a sound insulator pipe which incorporates nanotechnology. The product has obtained international certificates and has gained a large market share in Iran and also the Middle East countries. Silent Pipes won the best new product award of the $7^{\text {th }}$ Nanotechnology Festival and Exhibition in Iran in 2011.

\section{Research Approach and Methodology}

The research adopts a single longitudinal case study methodology. The justification for pursuing this approach rests heavily on the ability of qualitative data to offer insight into complex social processes that quantitative data cannot easily reveal (Eisenhardt and Graebner, 2007). Case studies are particularly suited to the study of complex networks where changes occur over time and multiple parties are involved (Halinen, \& Törnroos, 2005). The case study was purposively chosen to analyse a case of successful commercialization of an emerging technology in a network setting and in doing so to triangulate between theory, empirical context and method (Dubois and Gibbert, 2010). The focal actors in the case can be conceptualized as a triad. A triad is the smallest and simplest network and can offer insights, which cannot be achieved in the study of single actors or dyads (Ritter, 2000; Vedel et al., 2016). All networks can be deconstructed into triads for analytic purposes and to demonstrate network effects (Ritter, 2000).

Several sources of evidence were used in this study to enable triangulation of data, which is a technique of cross-checking data from multiple sources to search for regularities (Flick, 2014). One important advantage of using multiple sources of evidence is the development of converging lines of inquiry (Yin, 2009). Furthermore, multiple sources may contribute to "revealing aspects unknown to the researcher, i.e. to discover new dimensions of the research problem" (Dubois and Gadde, 2002; p.556). The primary sources of data for this study were semi-structured interviews with senior managers of the three organization involved in the development of the new product collected by two of the researchers. Also, participant observation provided the context for the research investigation as two of the researchers worked for INIC at the time and were directly engaged with both Pipepro and Nanopro during the collaboration process (for 3 years). In addition, company websites, annual reports, press releases, letters, news and other types of reports were used as sources of secondary data.

Table 1 shows the positions of the interviewees in each organization and the number of interviews conducted with each person. Each interview took about 2 hours. All interviews were recorded and then transcribed. In some cases the transcripts were reviewed again by the interviewees and the interviewee could add or edit information. All interviewees were offered the opportunity to review and edit interview transcripts, but some did not do it.

\section{Table 1. Interviewees Positions and Number of Interviews}

In qualitative data analysis, usually several levels of analysis are needed to extract both explicit and implicit meaning from the data (Flick, 2014). The analysis of data in this study is divided into two parts. First, a detailed description of the case was developed, drawing from the interviews and secondary sources of data. This includes a brief history of the collaboration and the actors involved. The results of first step of data analysis revealed that certain capabilities were crucial to drive the start of collaboration and new capabilities were 
developed during the collaboration and at the stage of commercialization and large-scale production.

The second step included a more analytical investigation of the case. In this step, thematic analysis was used to recognize the main themes in the qualitative data. In addition to interview transcripts as primary data sources, companies' annual reports, news, and all letters and written communications between the three partners were used in the analysis to better understand the collaboration process, role of actors and resource allocations for the project. In the second stage of analysis, we developed a template of data codes considering three main stages of collaboration and extracted changes in roles and capabilities of actors following the thematic analysis method of Cassel and Symon (2006). The template was developed and revised in the light of the on-going analysis (An example of the themes developed around the capabilities that drive collaboration is presented in the appendix).

Data quality was assessed using the criteria outlined by Hirschman (1986) of credibility, confirmability, transferability and dependability. To assure the credibility and confirmability of interpretations we used multiple investigators, multiple sources of evidence, and peer debriefing (Riege, 2003). We submitted case study reports to the scrutiny of key informant (including Pipepro CEO, the Nanopro founder and the Nanotech Fund director), and sought their responses as to its authenticity. To enhance dependability and minimize researcher idiosyncrasies data coding and analysis was done by two investigators (Creswell and Miller, 2000). Although the extent of transferability of the findings depends on the specifics of the context to which the interpretation is to be applied (Hirschman, 1986), it is expected that the research findings are applicable to the context of other emerging technologies.

\subsection{Case Overview}

The main actors involved in the development of the product include a large company that has been producing polypropylene water and wastewater pipes since 1995 (Pipepro), a technology-based start-up in the field of nanotechnology (Nanopro), and a governmental organization that played an intermediary role (INIC). Table 2 provides a brief description of the actors. Both the start-up and the incumbent firm experienced high growth as a result of the successful development and commercialization of the new product.

\section{Table 2. Description of network actors involved in the development of the new product}

Pipepro decided it needed to add a high-tech product to its product portfolio to enhance the national and international image of the company. In the first instance, they invited one of their international partner companies (a leading German firm in the pipe industry) to establish a joint venture in Iran but the foreign partner did not show any interest in investment. Therefore, in 2007, they started searching for Iranian research centers expert in the field of polymeric compounds and composites as they saw this as being key to their new development. The company planned to produce a three-layer pipe, with the middle layer consisting of polymers with sound insulation properties. To improve the mechanical properties of the middle layer, a nano-based additive was necessary to balance the fragility and sound insulation properties.

Pipepro monitored conferences and scientific papers in the field to find knowledgeable individuals in Iran. They also approached the INIC which could facilitate their connection to 
Nanopro, a newly established company with founders from a top technical university in Iran. There was a product with similar properties that Pipepro aimed for, which had been produced by a European company. Pipepro considered that product as a benchmark for their new product properties and aimed at producing a similar product with advanced properties. This enabled them to clearly define and communicate their required properties and features to the technology-based start-up. They were also aware of the details of required certificates for the product. During several meetings, Pipepro's needs were transparently presented to the start-up company along with required materials and some test equipment.

Finally, a cooperation agreement between Pipepro and Nanopro was signed. Based on the agreement, Pipepro covered half of the costs, defined the required technical specifications, provided its equipment for tests, and owned the exclusive intellectual property for nanocomposites applications in the construction field. The INIC covered the other half of the costs and supported the cooperation. The new product was developed after about three years. Initially, Nanopro was responsible for the research and development and later it launched large-scale production of the pipe's middle layer including the nano-based additive. The product was awarded quality certificates from the Fraunhofer Institute in Germany and its success has been demonstrated through the growth of its market share in Iran and the Middle East region.

As a result of the successful product development the processes are shared between Pipepro and Nanopro. Pipepro procures the raw materials including mineral materials and petrochemicals for Nanopro to produce the master-batches of the nano-composite needed for the product. Then using these master-batches Pipepro produces the three-layer silent pipes. Sales, marketing and distribution of the final product is performed by Pipepro. Outcomes of this include Pipepro gaining an international reputation and investing in advanced internal production processes. This included tripling the laboratory size and activities. The company has established a unit to produce pipe "connectors" which are complementary products for the silent pipe.

\section{Findings}

The findings are divided into sections that reflect three stages that influenced the development of operational and dynamic capabilities that were identified during the data analysis. These were: (1) capabilities that drive collaboration and joint new product development, (2) capabilities developed during the new product development process and (3) capabilities developed during the commercialization and large-scale production of the new product. In the following section, these capabilities are explained for each individual actor in the network (Table 3). Also, how the roles of actors have changed in the network during these three stages is presented.

\subsection{Capabilities Driving Collaboration and Joint New Product Development}

\subsubsection{Technology-based Start-up (Nanopro)}

Being a university spin-out, Nanopro had founders with research expertise in nanocomposites and polymers. The main reason for starting the company was that the founders 
sensed a great potential for applications of nano-composites in various industries in Iran and the Middle-East region. They were the first start-up company in Iran that started small scale $R \& D$ activities in this area.

"During my studies at Sharif University of Technology, I was a researcher at the Polymer Laboratory of the University, working closely with [Dr.Smith], a well-known senior academic in the polymer research, with whom we started Nanopro. ... Our research project on nano-composites and its applications, initially in the automobile industry and later in construction materials, was very promising and our objective was to develop the technology further at Nanopro and make it ready for industrial use. In addition to using facilities in the Polymer laboratory, we bought our own processing equipment to further develop our polymer blends and composites." Founder and CEO, Nanopro

Nanopro identified the opportunity that novel nano-composites could provide for various large industries. The company was started using personal investment from the founders and was initially located at the University incubator. Later, they secured funds for some of their research projects from the Ministry of Industry, Mine and Trade.

\subsubsection{Incumbent Firm (Pipepro)}

Being the sales agent and remote producer of the leading German company in the region, Pipepro had established production facilities in two plants. It was already a well-known brand in the pipe industry in the country as a licensee - producer of polypropylene water and wastewater pipes for buildings. They had established sales and distribution channels in the country. In addition to these operational capabilities, Pipepro had several dynamic capabilities that drove the collaboration and initiation of the new product development process:

\section{Management Commitment to invest in NPD and Risk Taking}

Top management in Pipepro had a strong belief in the importance of R\&D-based and innovative activities. The innovative direction of leading companies in developed countries had always driven the firm's strategic direction, for example, the R\&D manager from Pipepro noted that:

"Most Iranian companies active in the area of construction materials follow the traditional structure of the industry and do not have much industrial $R \& D$. There is a tendency to go for the cheapest available option and not investing in innovative activities. This is not a sustainable decision. We have severe need to do industrial $R \& D$ to survive and that's why we deeply consider investment in doing research and coming up with new and enhanced products." R\&D Manager, Pipepro

The Pipepro founders had more than thirty years of experience in plumbing systems in the construction industry. They were pioneers in their field and maintained their leadership in this industry in Iran. The company's management team comprised two levels of managers, directors who were founders of the company with their sons as senior managers. This combination of established experience over 30 years and technology enthusiasm and willingness to take risk of the younger senior managers provided a unique combination of managerial capabilities for new product development: 
"The open approach of our young executives towards risk and decision making in uncertain technological environments along with flair, knowledge and accumulated experience of our directors have given us the advantage in deciding on new approaches for business development. We think that this is also the main cause of our management team's willingness and commitment to invest in R\&D based activities." CEO, Pipepro

Another important motivation for Pipepro behind entering the field of emerging technologies was enhancing its reputation in the international market. Despite having a good reputation and a long history in the pipe industry in the domestic market, the firm sees itself as a growing company that aims at expanding its activities regionally and internationally.

"Although we have a relatively large market-share in Iran, we still see ourselves as a growing company and we aim to target international markets ... but in order to enter international markets and compete in those markets, we certainly need novel products." CEO, Pipepro

\section{Technology Sensing}

One of the important capabilities of Pipepro before the collaboration was their technology sensing. They began their search for a nano-technologically inspired solution following market intelligence gained while visiting a trade fair in Germany. They also investigated competing technological solutions and the industries in which they have been applied. Pipepro monitored scientific and technical research centres and universities active in the polymer area in Iran and were aware of the limited number of technology-based companies in the country. They also approached INIC to look for nanotechnology-based solutions and contributors in this area.

\section{Market Insight}

Prior to the collaboration, Pipepro had developed market insight through deep investigation of the potential market for silent pipes in the country and in the middle-east region. They also analysed the areas in which they have competitive advantage in the region to inform their decisions about the new product:

"We recognized that we have certain advantages in the region for producing silent pipes. We had access to low cost raw materials, both minerals and petrochemicals. We had large-scale production capabilities with the potential to be further expanded. We also counted on our knowledge of the domestic and regional market and selected the product for development based on these criteria." Production Manager, Pipepro

\section{Network Vision}

As part of their strategy, Pipepro had always focused on their core capabilities and followed a partnership model. Based on this approach, Pipepro systematically searched for companies with complementary technological and innovative skills necessary for their product development. They had proficiency in initiating and managing long-term cooperation with other Iranian or foreign organizations.

"Since we started our business we have been proactively making partnerships with various organizations inside and outside the country. And our strategy has always been to be clear in setting relationship goals and expectations of partners. This approach has helped us develop long-lasting relationships with other organizations." CEO, Pipepro 


\subsubsection{Intermediary (INIC)}

In addition to the above capabilities of Nanopro and Pipepro, INIC's capabilities were very influential in shaping the opportunity and driving collaboration among the three partners. INIC played an important role in identifying areas of mutual interests, matching needs, and motivating Nanopro and Pipepro for starting joint development of the new product based on an emerging technology. Operational capabilities of INIC that drove collaboration include: part-financing the project and providing project insurance by covering the risks associated with pilot testing of the manufacturing of the new material. The significant dynamic capability of INIC at this stage was shaping the opportunity of joint NPD and minimizing threats. INIC guaranteed to Nanopro that they would ensure that the newly developed product found a market elsewhere if Pipepro refused to purchase it.

"As part of the support we provide to nanotech companies, we introduce them to large industrial firms to explore areas of possible collaboration. This was what we did in the case of Nanopro and introduced them to Pipepro. We had several meetings with representatives from both companies at INIC to start negotiations and investigating areas of mutual interest ... we provided partial funding and assured both sides that our support will continue during pilot manufacturing... Nanopro was concerned that after making various investments in the project, their time and human resources, to make it fully customized for Pipepro, what would happen if Pipepro refuses to purchase the final product ... we guaranteed to find other firms as their potential customers in that case." Industry Engagement Officer, INIC

\subsection{Capabilities Developed during Joint New Product Development}

Certain capabilities needed to be developed during the collaboration to keep the project running jointly. From the viewpoint of all actors, these capabilities have been vital for a fruitful joint development of a new product in the context of an emerging technology, considering the relatively long time span of joint development (i.e. three years).

\subsubsection{Technology-based Start-up (Nanopro)}

In this stage, Nanopro demonstrated and gained several operational capabilities and the dynamic capability of seizing technological co-development.

\section{Contract Compliance}

During the collaboration, Nanopro demonstrated compliance with the contract and ethical behaviour. Based on the contract, Pipepro had exclusive ownership of the intellectual property (IP) related to developing nano-composites for their application in pipes. This was agreed among parties because of the amount of investment Pipepro made for the project. Despite poor infrastructures for protecting IP in Iran, Nanopro remained committed to the contract by selling the developed material exclusively to Pipepro. This behaviour yielded a sustainable long-term relationship and growth on both sides of the relationship.

"As soon as the project got successful results in development of the nano-composite for silent pipes, other pipe producer companies approached Nanopro and asked for the novel material and/or the technology of producing it. However, Nanopro stuck to their 
agreement with Pipepro and didn't provide the material or technology to other companies." Industry Engamanet Expert, INIC

\section{Positioning}

Nanopro was aware that it had scientific and technological expertise but lacked business and management capabilities. Having a good understanding of the firm's position in the relationship and the wider network helped both them and Pipepro in decision making and allocation of activities.

"Both of us [Nanopro founders] have academic background and technological expertise, but, especially in the beginning, we lacked business and managerial skills ... Pipepro has experienced managers and a successful history... we were aware of these differences and knew our position as a start-up firm with technological know-how." Founder, Nanopro

\section{Operation Management}

During the collaboration, Nanopro also developed their operations management capability by learning how to align their activities with Pipepro in-line with Pipepro's demands (e.g. technical requirements, and production standards).

“... although the initial prototype we developed together was satisfactory for Pipepro, when we sent them the second version of nano-composites, they were not working well when mixed with other two layers of pipe ... similar technical problems arose when we had this back and forth type of prototype testing between us and Pipepro ... we tried to solve these technical problems by aligning our activities and production to the demand of Pipepro. In total, we set specific tests at four stages of the development process to make sure that the resulting composite has the exact specifications that Pipepro want ..." CEO, Nanopro

This capability was complementary to Pipepro's capabilities in setting clear specifications for the product which guided the whole joint development process. In this way, both Nanopro and Pipepro developed the seizing capability by selecting and negotiating which technologies and features are to be embedded in the product (i.e. seizing technological co-development).

\subsubsection{Incumbent Firm (Pipepro)}

During the joint development of the new product, Pipepro developed operational and dynamic capabilities which included the seizing capability of technological co-development with Nanopro. They also guided Nanopro in operations and advised them about strategic management.

\section{Supplier Management}

Once the initial agreement had been established, Pipepro was able to clearly specify their technical needs (including all the details required by standards and certifying bodies) and product requirements to Nanopro.

“... these requirements formed a significant portion of our work/order book during the initial stages of the collaboration." Production Manager, Nanopro

In turn, these requirements could be clearly communicated to Nanopro's suppliers within the wider network. As the development process continued and larger batches of the nano-enabled component were being produced, Pipepro got more and more engaged in the operations of 
Nanopro and proactively helped them by giving strategic guidance and directions in operations management.

"We developed a very productive relationship together ... Pipepro was particularly helpful in setting milestones for the product development, we set specific targets for production times and volumes together ... we produced detailed datasheets for Pipepro for each small or large batch of the components produced" CEO, Nanopro

\section{Lobbying}

Being pioneers in the field of polymeric pipes in Iran, Pipepro started lobbying and negotiating around setting the standards for the new product from the early stages of product development. They also tried to set the required regulation for silent pipes in the construction industry and building codes. This was an on-going process during the development and commercialization of the product.

\section{Developing Technology-oriented Organizational Culture}

Pipepro believed that technology did not only impact upon equipment. The company emphasized the importance of considering various dimensions of technological innovation such as the organizational culture which is necessary for development of a technology-based product. According to Pipepro's R\&D manager, during their 10-year collaboration with a leading German firm in the industry and through other international relationships, Pipepro was always trying to learn and gain the necessary organizational culture which it needed for development and production of new technology-based products. As evidence of the importance of learning across the whole company, a group of fifteen employees including senior and junior managers and engineers from across the whole company went on a number of fact-finding visits to their German partner company. The aim of the visits was to provide experience of how a successful innovative company works.

"Visiting the sites, laboratories, and production lines of our German partner - who is a leader in the pipe industry - interacting with their personnel and getting familiar with their attitudes toward technology-based products was very informative for our personnel ... we tried to learn from them and better understand how an innovative company generally works" R\&D Manager, Pipepro

\subsubsection{Intermediary (INIC)}

INIC continued their support during the collaboration. In particular, they financially supported both partners to get international certificates for the new product. Also, INIC facilitated communication between the two different companies. Pipepro, as a leading company in their field, had an accumulated knowledge of the industry. They considered Nanopro to be deficient in practical knowledge and industrial insight. On the other hand, Nanopro had a research and engineering background and regarded Pipepro as lacking the required theoretical knowledge. INIC helped both sides to reach a common ground in the collaboration. They also played a mediating role by resolving issues that arose between the other two actors.

"An example relates to when Nanopro used a new supplier and inadvertently introduced a fault into the product specification. INIC helped resolve the problems resulting from this which included helping Nanopro source more reliable suppliers and reassuring Pipepro 
that Nanopro had learnt valuable lessons relating to supplier management and quality control from the situation. ” Industry Engagement Officer, INIC

INIC developed the seizing capability of alignment of resources, both internally and externally. INIC supported Pipepro and Nanopro by providing additional resources (e.g. to get international product certificate) and alignment of resources between partners. They provided mechanisms to cope with dysfunctionality of resource allocation.

\subsection{Capabilities Developed during Large-scale Production}

All actors developed new capabilities during the commercialization and large-scale production of the new product. Overall, both Pipepro and Nanopro experienced high growth as a result of successful product launch and market acceptance. A major achievement for all three actors was a successful collaborative NPD model which they consider as a basis for future NPD projects in a network setting and in the context of emerging technologies. Also the capabilities developed by actors in this stage influenced capability development in the wider network. An example was the enhanced skills in specification development of material suppliers of both Pipepro and Nanopro. The following section elaborates the capabilities developed in the third stage.

\subsubsection{Technology-based Start-up (Nanopro)}

The major dynamic capability developed by Nanopro at this stage was transforming. The company transformed from a small start-up company to a medium-sized producer with expertise in development and production of a novel nano-composite. Nanopro continued renewal by implementing and refining its strategy of developing and commercializing nanocomposites and aimed to expand the application areas of the novel material.

\section{Large-scale Production of the Nano-enabled Component}

Nanopro experienced a high growth rate in this stage Because Nanopro viewed this collaboration as long-term, they invested in all the necessary production equipment and machinery to be able to cover the large-scale demand of Pipepro.

"During three years of collaboration we expanded our laboratory and production lines. Currently, we have four production lines with the capacity of 7000 tonnes per year." Production Manager, Nanopro

\section{Industrial scale R\&D and New Application Development}

By the time they began large-scale production, Nanopro had gained capabilities for conducting industrial-scale R\&D. More specifically, they had the capacity to disseminate the technology by developing new applications of the nano-enabled components in products other than pipes. This was an interesting avenue for future expansions of Nanopro and starting a similar collaboration model with incumbent firms in other industries. In addition, Pipepro was eager to start new collaborative projects and engage Nanopro in more joint R\&D based activities: 
"Since our joint project was successful we are beginning a new $R \& D$ stream with Nanopro to develop a new form of composites for connector pipes ... we believe this adds to the stability of our relationship" R\&D Manager, Pipepro

\section{National and International Reputation}

The successful new product development of involved actors was recognized nationally and internationally through participating in various commercial events and exhibitions. This had a positive impact on the reputation of Nanopro as a technology-based firm and attracted attention of other large industrial firms interested in applications of nano-composites in their area.

\subsubsection{Incumbent Firm (Pipepro)}

By this stage in the collaboration, Pipepro had changed their business model from being a sales agent and remote production facility to being able to compete with their German partner and other regional players in the pipe industry. In addition to the operational capabilities, Pipepro demonstrated a transforming capability in this stage.

\section{Production and Commercialization of the Nano-enabled Product}

Pipepro expanded its production to three large-scale production plants in the country. Following commercialization of the silent pipes, Pipepro now only imports German pipes for a few customers in Iran and the surrounding region. Their business has now been shifted to an independent ${ }^{1}$ producer of nano-enabled pipes. Their market share has also increased due to increasing national and regional demand for silent pipes. This has been accompanied by a readjustment in pricing with the new product only being around 10 per cent more than rival products (previously the imported products were almost twice the price of substitute products). They have also had to strengthen their marketing and sales capabilities by employing specialist technical sales personnel to support the sales of silent pipes. This is indicative of Pipepro both developing an independent network and also gaining production and whole-life cycle NPD capabilities. Pipepro gained the capability of offering the new product not only in the country, but also in the middle-east region and as a result enhanced their international reputation.

\section{Industrial scale R\&D}

This is a joint capability developed by both Pipepro and Nanopro. As a result of collaboration, Pipepro tripled the size of their laboratory and developed extensive R\&D capabilities. Both companies are eager to start new joint $R \& D$ projects and repeat the successful collaboration process in new technological areas.

\section{Standard setting in the pipe industry in the country}

In this stage of collaboration, Pipepro was able to largely influence standards setting for silent pipe quality. The company has also been influential in updating the Iranian building code and related standards in the construction industry in Iran. According to the Industry Engagement

\footnotetext{
${ }^{1}$ From licensor
} 
Officer at INIC, setting standards is one of the characteristics of the wider impact of the commercialization of nanotech-based products.

"This initiative taken by Pipepro is very much in-line with our national goals in development of nanotechnology at INIC and shows the importance of utilization and deployment of emerging technologies to the economy as a whole." Industry Engagement Officer, INIC

\section{Driving Technology Development of the Wider Network}

Collaboration between Pipepro and Nanopro and large-scale development of the new product resulted in the suppliers of mineral materials having to make changes to their production and quality systems. According to Pipepro's production manager, because most customers of these mineral materials suppliers were low-tech companies, they were not concerned about offering products with precise technical properties. This caused production challenges for both Pipepro and Nanopro. Pipepro was driving the technical requirements of the raw materials and worked closely with the mineral producers to ensure that consistent supplies of the specified products were available. They did this by encouraging the suppliers to utilize newer production technologies.

\subsubsection{Intermediary (INIC)}

The support of INIC continued in a different form in the commercialization and large-scale production of the nano-enabled product. INIC supported the companies, in particular Pipepro, in introducing the new product to international markets by part-financing participation in international trade fairs in different countries. They also promoted the product in the country through trade fairs and special events such as the annual Nanotechnology Festival.

\subsection{Interaction between Roles and Dynamic Capabilities}

Analysis of the capabilities developed within various stages of the collaboration process revealed diverse roles played by actors to co-construct the network with the aim of developing and commercializing a new product incorporating an emerging technology. These roles and the way they changed over time are shown in Table 4.

Table 3. Capability development by actors through different collaboration stages

Table 4. Actor's role changes during various stages of collaboration

We observed that there is a link between capabilities deployed and the roles played by the actors. In the pre-collaboration stage, sensing capabilities were predominantly developed by actors. Having a Researcher role, Nanopro sensed the new opportunity of developing a technology-based solution for industrial firms in the area of polymers and composites. From a strategic perspective (NPD strategist), Pipepro sensed the opportunity to develop a technology-based product and realized the need for investment outside of their company to make this happen (Investor). INIC helped the other two actors in sensing and shaping the opportunity by acting as the Matchmaker, Financer and Insurer. 
The joint NPD process started when actors developed seizing capabilities and committed resources and devised a strategy to exploit the opportunity. During this stage both Nanopro and Pipepro mobilized their resources for co-development of technology and product features (Technology co-developers). In addition, Pipepro took a Guider role (directing Nanopro in operations management) as well as Lobbyist to promote the market for the silent pipe product. As a Mediator, INIC facilitated the collaboration by utilizing their seizing capabilities to align the resource allocation of other actors.

During the large-scale production and commercialization, actors mainly developed seizing and transforming capabilities. Nanopro became the nano-composite Producer and a strategic supplier of Pipepro for producing silent pipes. Pipepro transformed to a large company with expansion in its R\&D, production and international activities. They also played the important role of Standard setter in the country which resulted in expansion of the domestic market for the novel product. INIC continued their Supporter role and in particular had positive impact as product Promoter. The transforming capability of all actors was evident as they implemented knowledge transfer to new areas of activity. For Nanopro, this was observed in transferring their knowledge and know-how to new application areas for nano-composites (New application developer). For Pipepro, in addition to new application areas, they transferred their knowledge to new markets (Seller, Marketer, and International Player). INIC also used the knowledge and experience gained during this collaboration in other similar network settings formed for commercialization of nanotechnology.

\section{Discussion and Conclusion}

\subsection{Theoretical Implications}

This study broadens our understanding about evolution of capabilities and roles of organizations in a network formed for development of a new product incorporating an emerging technology. The findings illustrate that different capabilities and roles are needed during different phases of the development, indicating that success depends upon the ongoing development of capabilities and roles.

Our longitudinal case demonstrated how the capability sets of the actors developed throughout the collaboration, including both operational and dynamic capabilities. Actors developed sensing capabilities in the pre-collaboration stage which drove joint new product development in a network setting. During the collaboration, seizing capabilities were developed where resource commitment and alignment of resources among actors were essential. Capabilities gained through commercialization and large-scale production were predominantly transforming capabilities where actors realigned their structure and had positive impact on capability development in the wider network. Our findings indicate that all network actors need to develop and utilize dynamic capabilities in all areas of sensing, seizing and transforming over time (during the whole collaboration period) to be able to innovate and successfully commercialize a novel product incorporating an emerging technology. These findings provide a novel insight into development and evolution of dynamic capabilities for joint NPD and commercialization of emerging technologies not just within organizations (Salvato, 2009), but also in a network setting (Nordin et al., 2018). Dynamic capabilities enable firms to upgrade their ordinary capabilities and direct these and the capabilities of network partners, toward high-payoff endeavors (Teece, 2018). Our empirical study reveals 
more explicitly which operational and dynamic capabilities are needed at each stage of collaboration and contributes to our understanding of why certain capabilities were developed in the network over time. These findings enhance our understanding of the emerging business nets and network management capabilities that are required in this type of network including network visioning and orchestration (Möller and Svahn, 2003; Möller and Halinen, 2017).

Our findings also support the view that collaboration and co-creation processes in the network promote the generation and development of dynamic capabilities linked to innovation (Cabanelas et al., 2013; Preikschas et al., 2017). This was evident in the directed capability enhancement of the technology-based start-up by the incumbent firm and provision and support of the intermediary during the joint new product development process (Johnsen and Ford, 2006). Also, after successful production and commercialization of the new product, the incumbent firm looked to the technology-based partner to transform the developed knowledge and capabilities to new application areas and exploit new opportunities that occurred as a result of the partnership (Hill and Rothaermel, 2003; Möller \& Törrönen; 2003). Moreover, the collaboration between the three partners had consequences for capability development by other actors in the wider network including the incumbent firm's and the start-up's suppliers of raw materials (Chou \& Zolkiewski, 2012). In sum, as a result of the collaboration, actors in the triad and the wider network developed complementary capabilities that were essential for successful new product development and commercialization.

Last but not least, the study enriches our understanding of the link between actors' roles and capabilities. We found that development of certain dynamic capabilities enables actors to take on new roles as the collaboration continues through various stages. This responds to the call for empirical research to deepen the understanding of mechanisms affecting role of actors in networks and the change forces at play in embedded relational situations for firms (Nyström, et al., 2017). We revealed how diverse actors take on new roles in order to be successful when dealing with an emerging technology in a network setting. Whilst the roles identified here are all not the same as those identified by Story et al., (2011) they confirm the centrality of role performance during the commercialization process of emerging technologies.

\subsection{Managerial Implications}

Our paper has significant implications for diverse organizations dealing with emerging technologies. We have seen the evolutionary path of ordinary operational capabilities, through to the dynamic capabilities of sensing, seizing and transforming and how they relate to the position and role of actors in the network in the context of commercialization of an emerging technology. Technology-based start-ups, incumbent firms and intermediary organizations must be able to undergo this transformation of capabilities through interactions in the network and take on new roles if they are going to successfully develop and commercialize emerging technologies. Our findings highlight which roles (Table 4) and capabilities (Table 3) are needed at each stage of collaboration and could be used as a guide for managers to plan and analyse their behaviours at various stages of collaboration in the network. These insights could be particularly important for company managers and policy makers that aim to develop and/or encourage development of emerging technologies (e.g. nano-enabled products) in the context of developing countries where the established knowledge-bases of large industrial firms are absent and collaboration and mobilizing new sources of knowledge and capabilities outside their firm boundaries is a prerequisite for success. By anticipating the type of 
capabilities organizations and their partners need to develop and having a clear understanding of their roles during the collaboration, they can decrease the risk of failure in joint NPD and avoid extreme dependency on partners.

\subsection{Limitations and Further Research}

As is the case with any research, the findings should be considered within the context of limitations. Qualitative research and case studies have often been criticised for generating results that are less generalizable than those of large-sample, quantitative methods (Tsang, 2014). Although we relied on a variety of primary and secondary data sources, one of the limitations of this study is that it focused on only one case of an emerging technology network. Therefore, it might provide limited representational generalizability. However, the findings of our longitudinal study provide theoretical generalizability which pertains to development and extension of theory through empirical evidence and seeing particular cases as "opportunities for further refining our hitherto conceptualizations of general processes" (Tsoukas, 2009; p.286).

This study focused on a collaborative network for development of a nano-enabled product. Although actors were involved in development of some complementary process innovations, major focus of actors was on product innovation. Future studies could explore evolution of capabilities and roles in a network for development and commercialization of process and service innovations and compare the type of capabilities developed and roles played by actors.

\section{References}

Aarikka-Stenroos, L., Sandberg, B. \& Lehtimäki, T. 2014. Networks for the commercialization of innovations: A review of how divergent network actors contribute. Industrial Marketing Management, 43, 365-381.

Ahuja, G. 2000. Collaboration networks, structural holes, and innovation: A longitudinal study. Administrative Science Quarterly, 45, 425-455.

Andersen, M.M. 2011. Silent innovation: corporate strategizing in early nanotechnology evolution. The Journal of Technology Transfer, 36, 680-696.

Ansari, S. \& Krop, P. 2012. Incumbent performance in the face of a radical innovation: Towards a framework for incumbent challenger dynamics. Research Policy, 41(8), $1357-1374$.

Birkinshaw, J., Bessant, J. \& Delbridge, R. 2007. Finding, Forming, and Performing: Creating Networks for Discontinuous Innovation. California Management Review, 49, 67-84.

Cabanelas, P., Omil, J.C. \& Vázquez, X.H., 2013. A methodology for the construction of dynamic capabilities in industrial networks: The role of border agents. Industrial Marketing Management, 42(6), 992-1003.

Caloffi, A., Rossi, F. \& Russo, M. 2014. What makes SMEs more likely to collaborate? analysing the role of regional innovation policy. European Planning Studies, 23(7), 1245-1264.

Cassel, C., \& Symon, G. 2006. Essential Guide to Qualitative Methods in Organizational Research. SAGE Publications: London. 
Chou, H.-H. \& Zolkiewski, J. 2012. 'Managing Resource Interaction as a Means to Cope with Technological Change', Journal of Business Research 65(2), 188-195.

Colombo, M.G., Grilli, L. \& Piva, E. 2006. In search of complementary assets: The determinants of alliance formation of high-tech start-ups. Research Policy, 35, 11661199 .

Creswell, J. W. \& Miller, D. L. 2000. Determining Validity in Qualitative Inquiry. Theory into Practice, 39, 124-130.

Dubois, A., \& Gadde, L.-E. 2002. Systematic Combining: an Abductive Approach to Case Research. Journal of Business Research, 55, 553-560.

Dubois, A., \& Gibbert, M. 2010. From complexity to transparency: managing the interplay between theory, method and empirical phenomena in IMM case studies. Industrial Marketing Management, 39, 129-136.

Easingwood, C., \& Koustelos, A. 2000. Marketing High Technology: Preparation, Targeting, Positioning, Execution. Business Horizons, 43, 27-34.

Eisenhardt, K.M,. \& Graebner, M.A. 2007. Theory Building from Cases: Opportunities and Challenges. Academy of Management Journal, 50, 25-32.

Eisenhardt, K.M. \& Martin, J.A. 2000. Dynamic Capabilities: What Are They, Strategic Management Journal, 21(10/11), 1105-1121.

Flick, U., 2014. An Introduction to Qualitative Research. London: SAGE Publications.

Ford, D., Gadde, L.-E., Håkansson, H. \& Snehota, I. 2003. Managing business relationships $\left(2^{\text {nd }}\right.$ ed.). Chichester: Wiley.

Genet, C., Errabi, K. \& Gauthier, C. 2012. Which model of technology transfer for nanotechnology? A comparison with biotech and microelectronics. Technovation, 32, 205-215.

Gulati, R., 1999. Network location and learning: The influence of network resources and firm capabilities on alliance formation. Strategic management journal, 20(5), 397-420.

Hagedoorn, J. 1993. Understanding the Rationale of Strategic Technology Partnering: Interorganizational Modes of Cooperation and Sectoral Differences. Strategic Management Journal, 14, 371-385.

Harryson, S.J., 2008. Entrepreneurship through relationships-navigating from creativity to commercialisation. R\&D Management, 38(3), 290-310.

Halinen, A., \& Törnroos, J-A. 2005. Using case methods in the study of contemporary business networks. Journal of Business Research, 58(9), 1285-1297.

Hemert, P., Nijkamp, P. \& Masurel, E. 2013. From innovation to commercialization through networks and agglomerations: analysis of sources of innovation, innovation capabilities and performance of Dutch SMEs. The Annals of Regional Science, 50, 425-452.

Hill, C.W.L., \& Rothaermel, F.T. 2003. The Performance of Incumbent Firms in the Face of Radical Technological Innovation. The Academy of Management Review, 28, 257-274.

Hirschman, E. C. 1986. Humanistic Inquiry in Marketing Research: Philosophy, Method, and Criteria. Journal of Marketing Research, 23, 237-249. 
Howells, J. 2006. Intermediation and the role of intermediaries in innovation. Research Policy, $35,715-728$.

Hung, S.-C. \& Chu, Y.-Y. 2006. Stimulating new industries from emerging technologies: challenges for the public sector. Technovation, 26, 104-110.

Johnsen, R.E., \& Ford, D. 2006. Interaction capability development of smaller suppliers in relationships with larger customers. Industrial Marketing Management, 35, 10021015.

Lambe, C.J., \& Spekman, R.E. 1997. Alliances, External Technology Acquisition, and Discontinuous Technological Change. Journal of Product Innovation Management, $14,102-116$.

Laredo, P. 2008. Positioning the work done on nano S\&T associated to PRIME. Nanotechnology Science Mapping and Innovation Trajectories. Manchester, UK.

Maine, E., \& Garnsey, E. 2006. Commercializing generic technology: The case of advanced materials ventures. Research Policy, 35, 375-393.

Maine, E., Lubik, S., \& Garnsey, E. 2012. Process-based vs. product-based innovation: Value creation by nanotech ventures. Technovation, 32, 179-192.

Mowery, D.C. 2011. Nanotechnology and the US national innovation system: continuity and change. The Journal of Technology Transfer, 36, 697-711.

Möller, K. and Halinen, A., 2017. Managing business and innovation networks-From strategic nets to business fields and ecosystems. Industrial Marketing Management, 67, 5-22.

Möller, K. and Svahn, S., 2003. Managing strategic nets: A capability perspective. Marketing theory, 3(2), 209-234.

Möller, K., \& Törrönen, P. 2003. Business suppliers' value creation potential. Industrial Marketing Management, 32(2), 109-118.

Möller, K. 2010. Sense-making and agenda construction in emerging business networks: How to direct radical innovation. Industrial Marketing Management, 39, 361-371.

Nordin, F., Ravald, A., Möller, K. \& Mohr, J.J., 2018. Network management in emergent high-tech business contexts: Critical capabilities and activities. Industrial Marketing Management. https://doi.org/10.1016/j.indmarman.2017.09.024

Nyström A., Ramstrom J. \& Törnroos J. 2017. Conceptualizing mechanisms influencing strategizing in business networks, Journal of Business \& Industrial Marketing, 32 (6), 777-785.

OECD 2010. The Impacts of Nanotechnology on Companies: Policy Insights from Case Studies.

Pandza, K. \& Holt, R. 2007. Absorptive and transformative capacities in nanotechnology innovation systems. Journal of Engineering and Technology Management, 24, 347365 .

Perks, H. \& Jeffery, R., 2006. Global network configuration for innovation: a study of international fibre innovation. $R \& D$ Management, 36(1), 67-83. 
Powell, W. 1998. Learning from collaboration: knowledge and networks in the biotechnology and pharmaceutical industries. California Management Review, 40, 228-240.

Preikschas, M.W., Cabanelas, P., Rüdiger, K. \& Lampón, J.F., 2017. Value co-creation, dynamic capabilities and customer retention in industrial markets. Journal of Business \& Industrial Marketing, 32(3), 409-420.

Rampersad, G., Quester, P. \& Troshani, I., 2010. Managing innovation networks: Exploratory evidence from ICT, biotechnology and nanotechnology networks. Industrial Marketing Management, 39(5), 793-805.

Reypens, C., Lievens, A. \& Blazevic, V., 2016. Leveraging value in multi-stakeholder innovation networks: A process framework for value co-creation and capture. Industrial Marketing Management, 56, 40-50.

Riege, A.M., 2003. Validity and reliability tests in case study research: a literature review with "hands-on" applications for each research phase. Qualitative market research: An international journal, 6(2), 75-86.

Ritter, T., 2000. A framework for analyzing interconnectedness of relationships. Industrial Marketing Management, 29(4), 317-326.

Rothaermel, F.T. 2001. Incumbent's advantage through exploiting complementary assets via interfirm cooperation. Strategic Management Journal, 22, 687-699.

Rothaermel, F.T., \& Thursby, M. 2007. The nanotech versus the biotech revolution: Sources of productivity in incumbent firm research. Research Policy, 36, 832-849.

Salvato, C., 2009. Capabilities unveiled: The role of ordinary activities in the evolution of product development processes.Organization Science, 20(2), 384-409.

Salvato, C. \& Rerup, C., 2011. Beyond collective entities: Multilevel research on organizational routines and capabilities. Journal of Management, 37(2), 468-490.

Shapira, P., \& Youtie, J. 2011. Introduction to the symposium issue: nanotechnology innovation and policy - current strategies and future trajectories. The Journal of Technology Transfer, 36, 581-586.

Story, V., Hart, S., \& O’Malley, L. 2009. Relational resources and competences for radical product innovation. Journal of Marketing Management, 25, 461-481.

Story, V., O’Malley, L., \& Hart, S. 2011. Roles, role performance, and radical innovation competences. Industrial Marketing Management, 40, 952-966.

Teece, D.J., 2007. Explicating dynamic capabilities: the nature and microfoundations of (sustainable) enterprise performance. Strategic Management Journal, 28(13), 13191350 .

Teece, D.J., 2018. Business models and dynamic capabilities. Long Range Planning, 51(1), 40-49.

Teece, D.J. \& Pisano, G. 1994. The Dynamic Capabilities of Firms: An Introduction, Industrial and Corporate Change, 3(3), 537-556. 
Tidd, J. \& Bessant, J. 2013. Managing Innovation: Integrating Technological, Market and Organizational Change, John Wiley \& Sons.

Tran, Y., Hsuan, J. \& Mahnke, V. 2011. How do innovation intermediaries add value? Insight from new product development in fashion markets. $R \& D$ Management, 41, 80-91.

Tsoukas, H. 2009. Craving for Generality and Small-N Studies: A Wittgensteinian Approach Towards the Epistemology of the Particular in Organization and Management Studies. In: Buchanan, D. H. \& Bryman, A. (eds.) The Sage Handbook of Organizational Research Methods. London: Sage Publications.

Vedel, M., Holma, A.M. \& Havila, V., 2016. Conceptualizing inter-organizational triads. Industrial marketing management,57, 139-147.

Winch, G.M., \& Courtney, R. 2007. The organization of innovation brokers: an international review. Technology Analysis \& Strategic Management, 19, 747-763.

Winter, S. 2003. Understanding dynamic capabilities, Strategic Management Journal, Vol. 24, No. 10, 991-995.

Yam, R.C.M., Lo, W., Tang, E.P.Y., \& Lau, A.K.W. 2011. Analysis of sources of innovation, technological innovation capabilities, and performance: An empirical study of Hong Kong manufacturing industries. Research Policy, 40, 391-402.

Yin, R. K. 2009. Case Study Research: Design and Methods, California, SAGE Publications.

Yu, D., \& Hang, C. C. 2010. A Reflective Review of Disruptive Innovation Theory. International Journal of Management Reviews, 12, 435-452.

Zeng, S. X., Xie, X. \& Tam, C. M. 2010. Relationship between cooperation networks and innovation performance of SMEs. Technovation, 30, 181-194.

Zhang, J. \& Wu, W.P., 2017. Leveraging internal resources and external business networks for new product success: A dynamic capabilities perspective. Industrial Marketing Management, 61, 170-181.

Zucker, L.G., \& Darby, M.R. 1997. Present at the biotechnological revolution: transformation of technological identity for a large incumbent pharmaceutical firm. Research Policy, 26, 429-446. 
Appendix: Template for data analysis - Example of themes developed around the capabilities that drive collaboration

\section{- Nanopro}

○ R\&D projects

- Publications

○ University Collaboration

- Social connections

- Research links

- Facilities

- Pipepro

- Experience

- Production experience

- International connections

- Management Commitment

- invest in NPD

- Risk Taking

- Young risk taking managers

- International portfolio development

- Experienced leaders

- Network vision

- Overcoming narrow search horizons

- Searching for technology outside the company

- Participating in international industrial fairs

- Scanning academic sources inside the country

- Relational experience

- Local

- International

○ Market insight

- Market knowledge

- Domestic

- Regional

- Understanding customer needs

○ NPD Management

- Cost evaluation

- Local vs. international

- Access to raw materials

- INIC

○ Matchmaking

- Encouraging collaboration

- Minimizing risks

- Building up trust

$\circ$ Financer

- Providing funds 


\section{EXPLORATION OF CAPABILITY AND ROLE DEVELOPMENT IN AN EMERGING TECHNOLOGY NETWORK}

Table 1. Description of network actors involved in the development of the new product

\begin{tabular}{|c|c|c|c|}
\hline Actor & $\begin{array}{l}\text { Year of } \\
\text { Establishment }\end{array}$ & Main Activity & Observations \\
\hline $\begin{array}{l}\text { Incumbent Firm } \\
\text { (Pipepro) }\end{array}$ & 1995 & $\begin{array}{l}\text { Producing polypropylene } \\
\text { water and wastewater pipes } \\
\text { for buildings (having } 13 \\
\text { product categories) }\end{array}$ & $\begin{array}{l}\text {-Three manufacturing plants in two } \\
\text { industrial districts in Iran, with } \\
\text { headquarter in Tehran } \\
\text {-Substantial domestic market share in } \\
\text { pipe industry } \\
\text {-Large international competitors }\end{array}$ \\
\hline $\begin{array}{l}\text { Technology-based } \\
\text { Start-up } \\
\text { (Nanopro) }\end{array}$ & 2007 & $\begin{array}{l}\text { Producing advanced } \\
\text { polymer composites and } \\
\text { providing engineering } \\
\text { consultancy for selection } \\
\text { and deployment of } \\
\text { advanced materials }\end{array}$ & $\begin{array}{l}\text {-Knowledge-based university spin-off } \\
\text {-Winner of the first award of National } \\
\text { Sheikh-Bahai Technopreneurship } \\
\text { Festival } \\
\text {-Was selected as top three nanotech } \\
\text { firms in the } 5^{\text {th }} \text { Nanotechnology } \\
\text { Festival in Iran in } 2011\end{array}$ \\
\hline $\begin{array}{l}\text { Iran } \\
\text { Nanotechnology } \\
\text { Initiative Council } \\
\text { (INIC) }\end{array}$ & 2003 & $\begin{array}{l}\text { Main body responsible for } \\
\text { supporting development of } \\
\text { nanotechnology in the } \\
\text { country }\end{array}$ & $\begin{array}{l}\text {-Promotes cooperation of newly } \\
\text { established firms with existing } \\
\text { industrial companies for development } \\
\text { of nanotechnology }\end{array}$ \\
\hline
\end{tabular}

Table 2. Interviewees Positions and Number of Interviews

\begin{tabular}{|c|c|c|c|c|c|}
\hline $\begin{array}{l}\text { Incumbent Firm } \\
\text { (Pipepro) }\end{array}$ & $\begin{array}{l}\text { Number of } \\
\text { Interviews }\end{array}$ & $\begin{array}{l}\text { Technology- } \\
\text { based Start-up } \\
\text { (Nanopro) }\end{array}$ & $\begin{array}{l}\text { Number of } \\
\text { Interviews }\end{array}$ & $\begin{array}{l}\text { Intermediary } \\
\text { (INIC) }\end{array}$ & $\begin{array}{l}\text { Number of } \\
\text { Interviews }\end{array}$ \\
\hline CEO, Founder & 3 & CEO, Founder & 3 & $\begin{array}{l}\text { Industry } \\
\text { Engagement } \\
\text { Officer }\end{array}$ & 3 \\
\hline R\&D Manager & 2 & $\begin{array}{l}\text { Manager, Board } \\
\text { of Directors }\end{array}$ & 2 & $\begin{array}{l}\text { Industry } \\
\text { Engagement } \\
\text { Expert }\end{array}$ & \\
\hline $\begin{array}{l}\text { Production } \\
\text { Manager }\end{array}$ & 2 & $\begin{array}{l}\text { Production } \\
\text { Manager }\end{array}$ & 2 & $\begin{array}{l}\text { CEO, } \\
\text { Nanotech } \\
\text { Fund }\end{array}$ & \\
\hline
\end{tabular}


Table 3. Capability development by actors through different collaboration stages

\begin{tabular}{|c|c|c|c|c|}
\hline \multirow[t]{2}{*}{ Actors } & \multirow{2}{*}{ 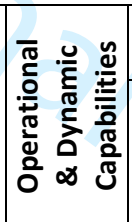 } & \multicolumn{3}{|c|}{ Capability Development } \\
\hline & & $\begin{array}{l}\text { Capabilities driving collaboration } \\
\text { and joint new product development }\end{array}$ & $\begin{array}{c}\text { Capabilities gained during new product } \\
\text { development }\end{array}$ & $\begin{array}{c}\text { Capabilities gained during } \\
\text { commercialization and large-scale } \\
\text { production (collaboration continues) }\end{array}$ \\
\hline \multirow[t]{2}{*}{ Nanopro } & 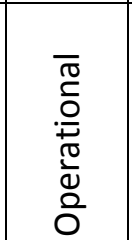 & $\begin{array}{l}\text { - Technical expertise and small } \\
\text { scale R\&D on nano-composites }\end{array}$ & $\begin{array}{l}\text { - Contract compliance } \\
\text { - Positioning } \\
\text { - Operation management in-line with } \\
\text { partner demands (e.g. timing, technical } \\
\text { requirements, and production standards) }\end{array}$ & $\begin{array}{l}\text { - Large scale production of the nano- } \\
\text { enabled component of the new product } \\
\text { - Industrial scale R\&D } \\
\text { - National and International reputation }\end{array}$ \\
\hline & 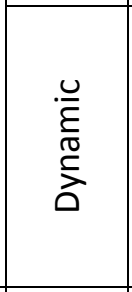 & $\begin{array}{l}\text { - Sensing the potential of nano- } \\
\text { composites' applications in } \\
\text { meeting the needs of large } \\
\text { industrial firms }\end{array}$ & - Seizing technological co-development & $\begin{array}{l}\text { - Transforming to a medium-sized } \\
\text { technology-based producer company } \\
\text { - Developing new applications for the } \\
\text { novel nano-composites } \\
\text { - Influencing the capability development } \\
\text { in the wider network }\end{array}$ \\
\hline \multirow[t]{2}{*}{ Pipepro } & 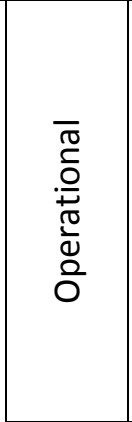 & $\begin{array}{l}\text { - Large-scale production in two } \\
\text { plants } \\
\text { - Established sales and distribution } \\
\text { channels }\end{array}$ & $\begin{array}{l}\text { - Supplier management (e.g. skills in } \\
\text { specification development) } \\
\text { - Lobbying } \\
\text { - Developing technology-oriented } \\
\text { organizational culture }\end{array}$ & $\begin{array}{l}\text { - Production of the new nano-enabled } \\
\text { product in } 3 \text { production plants } \\
\text { - Industrial scale R\&D } \\
\text { - Sales and marketing of new technology- } \\
\text { based product (competing with the } \\
\text { German leader firm in the region) } \\
\text { - Standard setting in the pipe industry in } \\
\text { the country } \\
\text { - International reputation }\end{array}$ \\
\hline & 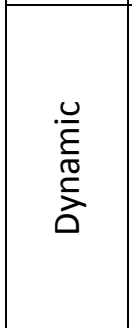 & $\begin{array}{l}\text { - Management commitment to } \\
\text { NPD \& risk taking } \\
\text { - Technology sensing } \\
\text { - Market insight } \\
\text { - Network Vision: Realized the } \\
\text { need for agility outside of the } \\
\text { company }\end{array}$ & $\begin{array}{l}\text { - Seizing technological co-development } \\
\text { - Guiding Nanopro in operations and } \\
\text { advising them in strategic management }\end{array}$ & $\begin{array}{l}\text { - Learning and know-how integration } \\
\text { - Influencing the capability development } \\
\text { in the wider network }\end{array}$ \\
\hline
\end{tabular}




\begin{tabular}{|c|c|c|c|c|}
\hline \multirow[t]{2}{*}{ Actors } & \multirow{2}{*}{ 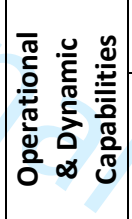 } & \multicolumn{3}{|c|}{ Capability Development } \\
\hline & & $\begin{array}{l}\text { Capabilities driving collaboration } \\
\text { and joint new product development }\end{array}$ & $\begin{array}{c}\text { Capabilities gained during new product } \\
\text { development }\end{array}$ & $\begin{array}{c}\text { Capabilities gained during } \\
\text { commercialization and large-scale } \\
\text { production (collaboration continues) }\end{array}$ \\
\hline \multirow[t]{2}{*}{ INIC } & 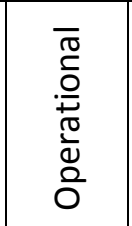 & $\begin{array}{l}\text { - Part-financing the NPD project } \\
\text { - Project insurance }\end{array}$ & $\begin{array}{l}\text { - Supporting partners to get international } \\
\text { product certificates }\end{array}$ & $\begin{array}{l}\text { - Supporting companies in introducing the } \\
\text { new product to international markets }\end{array}$ \\
\hline & $\begin{array}{l}\frac{u}{E} \\
\stackrel{0}{\sigma} \\
\stackrel{0}{\sigma}\end{array}$ & $\begin{array}{l}\text { - Shaping the opportunity and } \\
\text { minimizing threats: Matching and } \\
\text { motivating potential partners to } \\
\text { collaborate on what constitutes } \\
\text { the mutual interest }\end{array}$ & $\begin{array}{l}\text { - Alignment of resources between } \\
\text { partners: Providing a common ground in } \\
\text { collaboration and resolving issues raised } \\
\text { between the other actors }\end{array}$ & $\begin{array}{l}\text { - Support other actors in knowledge- } \\
\text { transfer and reaching new markets }\end{array}$ \\
\hline
\end{tabular}


Table 4. Actor's role changes during various stages of collaboration

\begin{tabular}{|l|l|l|l|}
\hline \multirow{2}{*}{ Actors } & \multicolumn{3}{|c|}{ Roles } \\
\cline { 2 - 4 } & Prior to collaboration & During the NPD process & $\begin{array}{l}\text { During large-scale production } \\
\text { (collaboration continues) }\end{array}$ \\
\hline Nanopro & - Researcher & - Technology co-developer & $\begin{array}{l}\text { - Producer of nano-enabled } \\
\text { component } \\
\text { - New application developer }\end{array}$ \\
\hline Pipepro & $\begin{array}{l}\text { - Investor } \\
\text { - NPD Strategist } \\
\text { - Producer of a low-tech } \\
\text { product as a licensee }\end{array}$ & $\begin{array}{l}\text { - Lobbyist } \\
\text { - Technology co-developer }\end{array}$ & $\begin{array}{l}\text { - Independent Producer of the } \\
\text { final nano-enabled product } \\
\text { - Standard Setter } \\
\text { - International Player }\end{array}$ \\
\hline INIC & $\begin{array}{l}\text { - Matchmaker } \\
\text { - Financer } \\
\text { - Insurer }\end{array}$ & - Mediator & - Supporter and Promoter \\
\hline
\end{tabular}

